\title{
Energy return on investment (EROI) of solar PV: an attempt at reconciliation
}

\author{
Michael Carbajales-Dale, Marco Raugei, Vasilis Fthenakis, Charles Barnhart
}

\section{INTRODUCTION}

In a recent Point of View piece [1], William Pickard made an excellent case for the importance of energy return on investment (EROI) as a useful metric for assessing longterm viability of energy-dependent systems from bands of hunter-gatherers, to modern society and, finally to the specific case of a solar electricity generating project. The author then highlighted a seeming disparity between a number of different research groups

1) Fthenakis group at Brookhaven,

2) Prieto group in Madrid,

3) Weißbach group in Berlin, and

4) Brandt group at Stanford

all of whom have recently published values for the EROI (or similar metric) for solar photovoltaic (PV) technologies.

Unfortunately, in so doing, the author directly compares results calculated using different system boundaries, methodologies, and assumptions. It is the purpose of this response to (1) adjust the results for the four groups to better compare like systems and (2) outline details of two methodological issues common in the EROI literature. The objective of these two activities is to explain much of the apparent disparity between the different EROI values produced by the different research groups.

\section{BACKGROUND}

\section{A. Financial ROI and the birth of EROI}

The concept of a financial return on investment (ROI) has a long history, dating back at least to the early Twentieth Century and is often attributed to Donaldson Brown of the DuPont company [2]. The earliest use of the specific concept of an energy return on investment (at least that these authors could find) dates back to a pair of studies in 1960 by Smith on the energetic efficiency of conversion of energy in feed by sows during gestation and lactation [3], [4]. Charles Hall is often seen as the major proponent of the EROI concept. Hall's first use of the energy return ratio concept (though

M. Carbajales-Dale is with the Department of Environmental Engineering \& Earth Sciences, Clemson University SC 29672, USA; e-mail: madale@clemson.edu

M. Raugei is with the Department of Mechanical Engineering and Mathematical Sciences, Oxford Brookes University, Oxford OX33 1HX

V. Fthenakis is the Director of the Center for Life Cycle Analysis, Columbia University NY 10027, USA and senior scientist at Brookhaven National Laboratory, Upton NY 11980, USA

C. Barnhart is with the Huxley College of the Environment and Institute for Energy Studies, Western Washington University, Bellingham WA 98225, USA using the term "multiplying effect") was in a 1972 study on fish migration. Similar ratios were applied by other studies to energy transformation technologies, notably: Chapman and Mortimer's analysis of nuclear reactors, using the term net energy ratio [5]; the International Federation of Institutes for Advanced Study (IFIAS) Workshop, which calculated the energy requirement for energy, equal to $\frac{1}{E R O I}+1[6]$; Martha Gilliland's discussion of the relevance of net energy ratio to public policy; the Colorado Energy Research Institute (CERI) report, which calculated a series of energy ratios: $R_{1}, R_{2}$, and $\mathrm{R}_{3}$ [7]; and Sedlik's [net energy] gain function, to describe the dynamic behavior of energy transitions [8].

The specific term EROI was popularized in a 1986 publication by Hall, Cleveland and Kaufmann, Energy and Resource Quality [9]. In this book, the authors outlined the EROI for a number of different energy transformation processes.

Since that time, numerous reports, papers and books have been published on a variety of different aspects related to EROI. There have been many hundreds of papers calculating the EROI of energy transformation technologies (e.g. [10], studies calculating the EROI of energy industries [11], a geographic region (including the globe) [12], and even the minimum EROI required to maintain an industrial society [13]. Some authors have investigated the relationship between EROI and price for crude oil [14] and there has even been a special issue of a journal devoted to the topic [15].

\section{B. The four research groups}

We now give a quick overview of the EROI calculations produced by the four research teams identified by Pickard.

1) Fthenakis group at Brookhaven: The Fthenakis group are the most LCA-orientated of the four groups. The EROI ${ }_{e l}$ value that Pickard highlights (5.9) [10, Table 1] could be for either mono- or multi-crystalline silicon PV, with data coming from [16]-[18]. These authors calculate both the EROI as a direct ratio of the total electricity output to the cumulative energy demand (CED) (the value of 5.9 highlighted by Pickard, which they refer to as $\mathrm{EROI}_{e l}$ ), and the most commonly accepted EROI ${ }_{P E-e q}$ [19], whereby the electricity output is converted into 'primary energy equivalent', which for the same mono- or multi-crystalline Si PV gives $\mathrm{EROI}_{P E-e q}$ $=19$ [10, Table 1]. It is noted that an $\mathrm{EROI}_{P E-e q}$ of 60 was estimated by the authors for thin-film cadmium telluride (CdTe) PV systems operated under US-SW solar radiation.

2) Prieto group in Madrid: In their book, Prieto and Hall make a very detailed analysis ${ }^{1}$ to arrive at an EROI for the

\footnotetext{
${ }^{1}$ Though arguably, somewhat inconsistent in its definition of system boundary and arbitrary in its inclusion of a large number of non-energy inputs.
} 
solar PV industry in Spain of 2.4 [20, Chapter 7]. In Chapters 5 (energy output) and 6 (energy inputs) the authors lay out the information and assumptions used in the calculation. The physical (i.e., non-monetary) data pertaining to the solar modules themselves and balance of system comes from [17], [19], [21]. An average energy payback time (EPBT) of 3 years and lifetime of 25 years are used to calculate the $\mathrm{EROI}_{P E-e q}$ $=8.33$ value for this part of the system. No references are given for any other input data; though it appears that anecdotal worst cases of installations were generalized by the authors.

3) Weißbach group in Berlin: Weißbach et al. use older (2005-6) life cycle inventory data from [22] to derive an embodied energy for poly-crystalline silicon of 2102-2172 $\mathrm{MJ} / \mathrm{m}^{2}$ [23, Table 2], the variation coming from whether the $\mathrm{PV}$ is a rooftop (low) or field (high) installation. This is used to calculate an $\mathrm{EROI}_{e l}$ for Germany (irradiation $=1000$ $\mathrm{kWh} / \mathrm{m}^{2} / \mathrm{yr}$ ) of 4.0 (roof) or 3.8 (field) [23, Table 3], where no quality correction factor has been applied to the electricity output, i.e. both primary and electrical energy inputs are aggregated and compared directly with the electricity output. When a primary energy equivalence factor is applied to the electrical output (in order to be comparable with the other groups' results), the $\mathrm{EROI}_{P E-e q}$ calculated is 5.6 [23, Fig. 2], When harmonized to Southern European irradiation levels $\left(1,700 \mathrm{kWh} / \mathrm{m}^{2} / \mathrm{yr}\right)$ to compare it with those from groups 1$)$ and 2), the $\mathrm{EROI}_{P E-e q}$ becomes 9.5.

4) Brandt group at Stanford: Brandt et al. present a mathematical framework for calculating energy return ratios [24]. The framework is then used to present an application of the method to a highly simplified "toy" model of a solar-PV production system. It was not intended as a result that should then be compared directly with other EROI calculations. In fact, the authors had long discussions about whether or not to present a "real life" application of the method for this very reason. Be that as it may, the underlying LCI data come from [25]-[27] with inputs for steel and concrete being estimated (probably rather poorly!). The authors report the net energy return (NER), approximately equivalent to $\mathrm{EROI}_{e l}$, as 5.75 [24, Table 2], assuming a $15 \%$ capacity factor (compared with a global average of $\sim 12 \%$, [28]), equivalent to an irradiation of $1,750 \mathrm{kWh} / \mathrm{m}^{2} / \mathrm{yr}$ and performance ratio of $75 \%$. When the electricity output is expressed in terms of primary energy equivalent (based on the average efficiency of the electric grid), then $\mathrm{EROI}_{P E-e q} \approx 19$.

In summary then, the four groups present EROI values ranging from roughly $9 \pm 0.6$ (groups 2 and 3) to 19 (groups 1 and 4), when comparing equivalent systems and using an equivalent methodology, i.e. using a quality correction factor to account for primary to electrical energy conversion.

Having rectified some of the methodological inconsistencies among the results from the four groups, we shall now explore two other methodological issues which further explain some of the discrepancy between the results of the four groups.

\section{TWO METHODOLOGICAL ISSUES IN EROI ANALYSIS}

As stated in the Introduction, the second goal of this piece is to describe two issues common in EROI analysis. The first issue relates to the goal of the analysis, the second relates to the scope of the analysis. These terms (goal and scope) will be readily familiar to readers well versed in the methodology of lifecycle assessment (LCA) to which EROI analysis can be considered a parallel methodology, however it is worth outlining what we mean by goal and scope. The required first step in any LCA is goal definition and scope, during which (in accordance with International Standards Organization (ISO) guidelines), the analyst shall in defining the goal, "unambiguously state: the intended application, the reason for carrying out the study, the intended audience and whether the results are intended to be used in comparative assertions" (goal definition) and further, when defining the scope, "clearly describe: the product system(s) to be studied, functions of the system(s), the functional unit, allocation procedures, lifecycle impact methodology and types of impacts, interpretation to be used, data requirements, assumptions, value choices and optional elements, limitations, data quality requirements, type of critical review, if any, type and format of the report required for the study. " [29].

For our present purposes, it shall be enough to state that the goal should outline the purpose of the analysis and the scope should outline the function of the system under study. We will see how these two critical domains often lead to conflicting EROI analyses.

\section{A. Issues related to goal definition}

One objective of the goal definition is to state the purpose of the analysis. Specifically, for the present argument, we are interested in the reason for carrying out the study. As described in Section II, EROI analyses have in the past (and still are) carried out for a number of different reasons, including:

(A) descriptive assessment of the viability of a particular technology (e.g., solar satellite);

(B) comparative assessment of alternative energy technologies; or

(C) calculation of the (minimum) EROI to support an industrial society, or alternatively assessing the feasibility of some technology to (single-handedly) support an industrial society.

Clearly each of these studies has a very different aim and requires a distinct set of system boundaries and underlying assumptions. For instance, to calculate the EROI necessary to support society, one would need to include a whole host of resource investments that may not be accounted in a study of type (A) or (B).

Unfortunately, these differing aims are often not considered in EROI calculations. Weißbach et al. provide demonstrative examples. The authors state that they are calculating and comparing EROI for "typical" power plants [23, p.210] Such a paper would fall squarely under goal (B) outlined above., The authors make the requirement for some of technologies under evaluation to include some form of back-up storage, for the purposes of delivering "usable" electricity, meant to mean that "the consumer has an actual need for the energy at the moment it is available" and also that "energy is available when the consumer needs it." [23, p.212]. Solar and wind 
technologies are required to deploy up to ten days of storage, (presumably enough to effectively enable any one plant to become $100 \%$ load-following for $100 \%$ of the year), hydro also has some storage requirement, whereas non-renewable technologies have no storage requirement since, "the fuel is already the storage" [23, p.212]. This last requirement is questionable. Baseload providers (coal and especially nuclear) are unable to follow the pattern of electricity demand (to provide electricity only when "the consumer has an actual need") and so should be required to deploy at least some amount of storage.

Done thoroughly, this condition would require producing a dispatch model of the whole electricity supply and demand system and would be far beyond the stated goal of comparing "typical" power plants. Typical power plants (except some solar thermal) do not deploy energy storage. While it may be the case that a future grid system with higher penetration levels (or even composed solely) of intermittent technologies may require higher levels of storage, such an analysis would fall under a different goal (e.g., goal (C)) and require a different methodological framework to explore.

\section{B. Issues related to scope}

Scope definition enters into EROI analysis when comparing calculations at different levels of analysis, for example comparing the EROI of oil and gas (which to our knowledge, is only ever calculated at the organization, industry, or regional level) with the EROI of a wind turbine. To explain the problem with such a comparison, we will use the mathematical formulation for EROI presented by Pickard [1, p.1120].

He defines EROI as "the dimensionless ratio $H$, where

$$
H=\frac{\sum_{p=1}^{P}{ }_{p} E_{\text {out }}}{\left\{E_{<}+\sum_{p-1}^{P}{ }_{p} E_{\text {in }}+E_{>}\right\}} \cdots
$$

Simplification: If for all $p,{ }_{p} E_{\text {out }}=\left\langle{ }_{p} E_{\text {out }}\right\rangle$ and ${ }_{p} E_{\text {in }}=$ $\left\langle{ }_{p} E_{i n}\right\rangle$, then

$$
H=\frac{\left\langle{ }_{p} E_{\text {out }}\right\rangle}{\left\{\left\langle_{p} E_{\text {in }}\right\rangle+\frac{1}{P}\left[E_{<}+E_{>}\right]\right\}},
$$

Such a framework performs well for technologies analyzed at the project level. For example, in analyzing a wind farm, there is a certain energy requirement $E_{<}$for the purposes of preparing the site; extracting, processing and transporting the raw materials; manufacturing the turbines and transporting them to the site; and then installing them. The turbines produce $\left\langle{ }_{p} E_{\text {out }}\right\rangle$ units of energy every year for $P$ years and require $\left\langle{ }_{p} E_{i n}\right\rangle$ units of energy for their operation and maintenance. After $P$ years have passed, some energy $E_{>}$is required to remove the turbines and to remediate the site. In this case, the system lifetime $P$ is well defined and, as such, so is the EROI, $H_{\text {proj }}$ (now labeled with a subscript project to emphasize that metric is defined at the project level).

Compare this now with an analysis undertaken at some higher level of organization, for example the EROI of Pickard's hunter-gather society, $H_{s o c}$. This is a dynamic story. We are now interested in the flows of energy, and specifically the net energy. Clearly, we are now no longer just interested in the viability of any one energy gathering activity, but that the aggregate performance of all such activities must produce a surplus, $\left\langle_{p} E_{\text {surplus }}\right\rangle$, else the band will not survive. How then, do we define $H_{s o c}$ ?

Since the expected lifetime of the band is far longer (hopefully) than the lifetime of any particular energy gathering activity, then we could try neglecting $E_{<}$and $E_{>}$(i.e., $\frac{1}{P} \rightarrow 0$ to define the EROI as

$$
H_{\text {soc }}=\frac{\left\langle{ }_{p} E_{\text {out }}\right\rangle}{\left\langle{ }_{p} E_{\text {in }}\right\rangle}
$$

All well and good, but notice now that $H_{s o c}$ is not definable in terms of $H_{\text {proj }}$, not even as the weighted aggregate (as might be expected). The societal level picture is inherently dynamic, the EROI picture is a static one. In order to adapt the EROI into a societal-level metric, we must assume something about that society: that it is in steady-state!

Let us now look at how this issue plays out in EROI analysis. Prieto and Hall [20] use data from Spain to make a comprehensive analysis of the EROI of the solar electricity system. They begin with an analysis of project level data in terms of direct and embodied energy. They then incorporate financial data on the spending of those projects to capture energy embodied in indirect goods and services via a (somewhat) traditional hybrid analysis. However, their conversion of monetary inputs into energy units by means of simple 'energyto-money ratios', does not conform to a conventional energy input-output methodology [30]. In principle, the result from this calculation could however, still be counted as an example of $H_{\text {proj }}$. Their next step is to incorporate spending (investments) made at the level of Spain's whole solar industry. At this point, a scope change has occurred and the analysis is no longer the same. They are now calculating $H_{s o c}$, which is not comparable to $H_{p r o j}$. Remember also, that an important assumption for definition of $H_{s o c}$ is that the system is in steady-state. This condition is certainly not upheld in the case of Spain's solar industry for which, "progress" (i.e. growth in capacity) "has been impressive" [20, p.21].

Prieto and Hall state that the lower value of their EROI calculation is due to a more comprehensive analysis. This is indeed true. Many of the project level investments that they include (e.g., business traveling of project consultants) are not accounted in other analyses, making direct comparison difficult. Additionally, the authors also blur the line between calculating $H_{\text {proj }}$ and $H_{s o c}$, making comparison to other analyses more difficult again.

\section{CONCLUSIONS AND RECOMMENDATIONS}

In summary then, issues with goal are those where the stated purpose of the study is unclear, or some of the study's assumptions seem to conflict with the stated goal. We saw this in Weißbach et al.'s paper where the requirement of ten days of storage for wind and solar conflicts with the stated purpose of analyzing "typical power plants". Issues of scope are where the function of the system under study is not well defined or where the system boundary shifts during the analysis. This was 
observed in Prieto and Hall's analysis of Spain's PV industry, which begins with an evaluation of $H_{\text {proj }}$, but ends up as an evaluation of $H_{s o c}$.

In truth, net energy analysis can be properly viewed as a subset of more comprehensive environmental assessments, such as LCA. We recommend that net energy analysts pay closer attention to the guidelines for such analyses (ISO 14040) as a framework for conducting EROI analysis, particularly regarding the need to clearly define both the goal and scope of the study. We also recommend that the conventions outlined by the IEA PV Systems Programme Task 12 (Environmental, Health \& Safety) be followed in conducting EROI calculations [19], [31]. Additionally, EROI analysts aiming at goals (A) and (B) may do well to take a lead from financial analysts who calculate the levelized cost of electricity (LCOE). Adopting similar methodologies, system boundaries and accounting similar costs would facilitate both inter-technology comparison of EROI values as well as inclusion of EROI with other performance metrics (e.g. LCOE, water use or GHG emissions) to allow for multi-dimensional assessment of technologies.

We also recommend transparency on the part of analysts when presenting EROI results, to emphasize the level (project or 'society') at which an analysis was conducted, and caution on the part of readers when comparing the results from such studies.

On a personal note, the first author would like to see the term "EROI" dispensed with when discussing 'societal' level analyses, to avoid both confusion with project level analyses and attempts to directly compare the results. For a society composed of projects that have a lifetime of more than one year (which is generally the case, especially for industrial societies!), it is unclear in what sense the "return" in any one year is due to the "investments" in that same year. There are, however, other metrics (or alternative names for the same metric) which more accurately reflect the dynamic nature of such an analysis, for example, fractional re-investment [28] or energy profit ratio [32].

On a final note, Pickard also recommends "to gather the four analytical groups for an extended Summer Workshop" [1, p.1121]. Speaking as representative members of groups 1) and 4), the authors welcome the opportunity to participate in such a workshop.

\section{V.}

\section{REFERENCES}

[1] W. F. Pickard, "Energy return on energy invested (EROI): a quintessential but possibly inadequate metric for sustainability in a solar-powered world?[point of view]," Proceedings of the IEEE, vol. 102, no. 8, pp. 1118-1122, 2014.

[2] R. S. Kaplan, "The evolution of management accounting," in Readings in Accounting for Management Control (C. Emmanuel, D. Otley, and K. Merchant, eds.), Springer, 1992.

[3] D. Smith, "The yield and energy content of milk and the energetic efficiency of sows on different levels of nutrition during gestation and lactation," New Zealand Journal of Agricultural Research, vol. 3, no. 5, pp. 745-763, 1960.

[4] D. Smith, "The effect of condition at farrowing upon the subsequent milk yield and the efficiency of production," New Zealand Journal of Agricultural Research, vol. 3, no. 3, pp. 598-616, 1960.
[5] P. F. Chapman, G. Leach, and M. Slesser, "2. The energy cost of fuels," Energy Policy, vol. 2, no. 3, pp. 231-243, 1974.

[6] IFIAS, Energy Analysis Workshop on Methodology and Conventions: 25th-30th August, 1974, Guldsmedshyttan, Sweden. International Federation of Institutes for Advanced Study, 1974.

[7] A. G. Melcher, K. Maddox, C. Prien, T. Nevens, V. Yesavage, P. Dickson, J. Fuller, W. Loehr, R. Baldwin, and R. Bain, "Net energy analysis: An energy balance study of fossil fuel resources," tech. rep., Colorado Energy Research Institute, PO Box 366, Golden, CO 80401, 1976.

[8] B. R. Sedlik, "Some theoretical considerations of net energy analysis," in Symposium Papers: Energy Modeling and Net Energy Analysis, Institute of Gas Technology, Chicago, pp. 245-261, 1978.

[9] C. A. S. Hall, C. J. Cleveland, and R. Kaufman, Energy and Resource Quality: The Ecology of the Economic Process. John Wiley \& Sons, 1986.

[10] M. Raugei, P. Fullana-i Palmer, and V. Fthenakis, "The energy return on energy investment (EROI) of photovoltaics: Methodology and comparisons with fossil fuel life cycles," Energy Policy, 2012.

[11] N. Gagnon, C. Hall, and L. Brinker, "A Preliminary Investigation of Energy Return on Energy Investment for Global Oil and Gas Production," Energies, vol. 2, no. 3, pp. 490-503, 2009.

[12] R. Nogovitsyn and A. Sokolov, "Preliminary calculation of the eroi for the production of gas in russia," Sustainability, vol. 6, no. 10, pp. 6751$6765,2014$.

[13] C. A. Hall, S. Balogh, and D. J. Murphy, "What is the minimum eroi that a sustainable society must have?," Energies, vol. 2, no. 1, pp. 25-47, 2009.

[14] C. W. King and C. A. Hall, "Relating financial and energy return on investment," Sustainability, vol. 3, no. 10, pp. 1810-1832, 2011.

[15] C. A. Hall, "Introduction to special issue on new studies in eroi (energy return on investment)," Sustainability, vol. 3, no. 10, pp. 1773-1777, 2011.

[16] V. Fthenakis, M. Held, H. Kim, and M. Raugei, "Update of energy payback times and environmental impacts of photovoltaics," in 24th European Photovoltaic Solar Energy Conference and Exhibition, 2009.

[17] V. Fthenakis and H. C. Kim, "Photovoltaics: Life-cycle analyses," Solar Energy, vol. 85, no. 8, pp. 1609-1628, 2011.

[18] M. Held and R. Ilg, "Update of environmental indicators and energy payback time of cdte pv systems in europe," Progress in Photovoltaics: Research and Applications, vol. 19, no. 5, pp. 614-626, 2011.

[19] V. Fthenakis, H. Kim, R. Frischknecht, M. Raugei, P. Sinha, M. Stucki, and M. de Wild Scholten, Life cycle inventories and life cycle assessment of photovoltaic systems. International Energy Agency, Report IEA-PVPS T12-02:2011, October 2011, ISBN: 978-3-906042-01-5, 2011.

[20] P. A. Prieto and C. A. Hall, Spain's Photovoltaic Revolution: The Energy Return on Investment. Springer, 2013.

[21] V. Fthenakis and E. Alsema, "Photovoltaics energy payback times, greenhouse gas emissions and external costs: 2004-early 2005 status," Progress in photovoltaics: research and applications, vol. 14, no. 3, pp. 275-280, 2006.

[22] M. de Wild-Scholten and E. Alsema, "Environmental life cycle inventory of crystalline silicon photovoltaic system production-status 2005/2006," Energy Research Centre of the Netherlands, Petten, 2007.

[23] D. Weißbach, G. Ruprecht, A. Huke, K. Czerski, S. Gottlieb, and A. Hussein, "Energy intensities, erois (energy returned on invested), and energy payback times of electricity generating power plants," Energy, vol. 52, pp. 210-221, 2013.

[24] A. R. Brandt, M. Dale, and C. J. Barnhart, "Calculating systems-scale energy efficiency and net energy returns: A bottom-up matrix-based approach," Energy, vol. 62, pp. 235-247, 2013.

[25] A. Stoppato, "Life cycle assessment of photovoltaic electricity generation," Energy, vol. 33, no. 2, pp. 224-232, 2008.

[26] J. Carrillo Usbeck, V.; Pflieger and T. Sun, "Life cycle assessment of float glass," 2011.

[27] PE International AG, GaBi software and database, v4, 2006.

[28] M. Dale and S. M. Benson, "Energy Balance of the Global Photovoltaic (PV) Industry-Is the PV Industry a Net Electricity Producer?," Environmental science \& technology, vol. 47, no. 7, pp. 3482-3489, 2013.

[29] ISO, Environmental management - Life cycle assessment - Principles and framework. International Organisation for Standardization, 2006.

[30] C. W. Bullard, P. S. Penner, and D. A. Pilati, "Net energy analysis: Handbook for combining process and input-output analysis," Resources and energy, vol. 1, no. 3, pp. 267-313, 1978.

[31] V. Fthenakis, R. Frischknecht, M. Raugei, H. C. Kim, E. Alsema, M. Held, and M. de Wild-Scholten, Methodology Guidelines on Life Cycle Assessment of Photovoltaic Electricity, 2nd edition. International Energy Agency, Report IEA-PVPS T12-03:2011, November 2011, 2011. 
[32] J. Gever, R. Kaufmann, D. Skole, and C. Vorosmarty, Beyond oil : the threat to food and fuel in the coming decades. Niwot, Colo: University Press of Colorado, 3rd ed., 1991. 